\title{
August updates: people and places
}

\section{Staff updates at OLAW}

In April, the National Institutes of Health Office of Laboratory Animal Welfare (OLAW) announced several staff changes:

After 12 years as the OLAW's first Director of the Division of Policy and Education (DPE), Susan Silk has retired as of the end of 2018. Silk will continue to direct the Interagency Collaborative Animal Research Education (ICARE) Project but is succeeded as DPE Director by Neera Gopee, formerly a veterinary medical officer (VMO) in the Divisions of Assurances and Compliance Oversight. Gopee has a DVM degree from the University of the West Indies and $\mathrm{PhD}$ in toxicology from the University of Georgia and has been with OLAW since 2016.

Veterinarian Nicolette Petervary has also joined OLAW from US Department of Agriculture Animal Plant and Health Inspection Service Animal Care, where she served as National Animal Welfare Specialist. Petervary received her VMD degree the University of Pennsylvania School of Veterinary Medicine and will serve as a VMO at OLAW.

\section{PRIM\&R Distinguished Service Award}

PRIM\&R, a Boston-based organization dedicated to Public Responsibility in Medicine and Research that was founded in 1974, has given its 2018 Distinguished Service Award to B. Taylor Bennett, senior scientific advisor for the National Association of Biomedical Research. The award was established in 1996 "to honor the exceptional accomplishments of deserving PRIM\&R members" ... "who have made a significant impact in the field of research ethics, and have attained distinction in promoting the purpose and ideals of the organization through writing, teaching, or research."

Bennett was nominated for his contributions to humane animal research oversight and was presented the award at PRIM\&R's 2019 IACUC Conference, held in Bellevue, WA at the beginning of April.

\section{A new decade at the IMPC}

At its 10 year anniversary, the International Mouse Phenotyping Consortium (IMPC), an international collaboration of research centers with the goal to systematically knock out and phenotype every mouse gene (as of 2018, they've made it through 8000), has announced a new strategy for its next decade. The key goal for 2021-2030 "is to deliver broad-based genomic insights into the function of human genetic variation in both coding and non-coding sequences that underpins future developments in precision medicine, rare-disease, clinical genetics and healthy living," they write in the strategy's executive summary.

The strategy includes six detailed goals; those along with additional information can be found at mousephenotypes.org.

\section{Mispro expands on Long Island} Mispro Biotech Services, a preclinical services company founded in 2003 that provides vivarium operations and support to biotech and research clients, recently announced it is expanding its research with a new 18,000 square foot vivarium facility in the Broad Hollow Bioscience Park in Farmingdale, NY. The facility is Mispro's fifth overall and second in New York. Its first New York facility opened in 2010 in Manhattan, with other existing vivarium space in Cambridge, MA, Research Triangle Park, NC, and Montreal.

In a press release, CEO Philippe Lamarre commented, "New York is fast becoming one of the world's leading biotech hubs and opening a location in Farmingdale is a unique and exciting opportunity for us to serve a diverse community of life sciences innovators in the Long Island area."

The Broad Hollow Bioscience Park is a partnership between Cold Spring Harbor Laboratory and The Research Foundation for the State University of New York. Executive Director Greg Blyskal commented in the release, "Vivarium access for in vivo studies is much desired, and an exciting amenity for the life sciences community we have in the greater-Farmingdale area. It's also a great addition to our science park campus, where we offer lab and office space and have well-established affiliations with academic, state, and private research institutions with preclinical pipelines."

\section{Transactions complete}

Envigo, a provider of preclinical research models and research services company LabCorp have announced the completion of business transactions first announced in April. Through its Covance Drug Development segment, LabCorp has acquired Envigo's nonclinical contract research services business while Envigo has acquired the Covance Research Products business. As noted in the press release for the announcement, "the two companies will continue to collaborate through a multi-year, renewable supply agreement." The research models \& services business will operate under the brand name Envigo and is expected to employ over 1200 people globally and will focus on offering models, diets, and bedding.

\section{Ignition awards awarded}

The Washington National Primate Research Center (WaNPRC) and the Institute of Translational Health Sciences at the University of Washington have awarded two Ignition Awards for 2019. The pilot program awards will support University of Washington's Nikolai Dembrow and his project to develop a primate culture platform for studying the neuropathology of neurodegenerative disorders as well as Jonathan Ting from the Allen Institute of Brain Science, who is working to optimize and apply novel AAV vectors for studying the brain.

Gene editing evaluations in California The University of California, Davis has received $\$ 9$ million in funding from the NIH to evaluate the safety and efficacy CRISPR/Cas9 gene editing tools in nonhuman primates. Research will take place at a new center to be called the UC Davis Nonhuman Primate Testing Center for Evaluation of Somatic Cell Genome Editing Tools. Leaders of the research include Alice Tarantal, David Segal, and Dennis Hartigan-O'Connor.

Published online: 22 July 2019 https://doi.org/10.1038/s41684-019-0354-2 